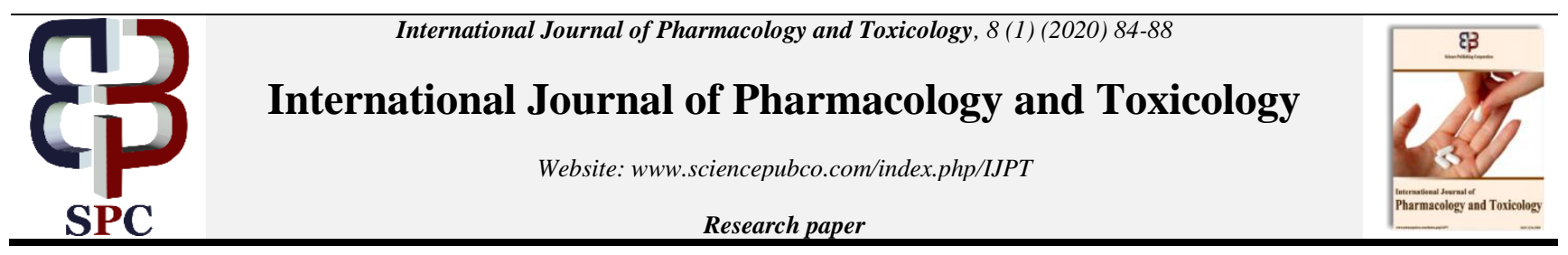

\title{
Determination of fipronil insecticide and its sulfone metabolite in internal organs of white albino rats
}

\author{
Yehia Mohamed Mohamed Salim* \\ Plant Protection Department, Faculty of Agriculture, Damanhour University, Damanhour, El-Beheira, PO Box 59, Egypt \\ *Corresponding author E-mail: yehia.salim@agr.dmu.edu.eg
}

\begin{abstract}
Fipronil is a popular insecticide against a wide range of household, urban, agricultural, animal pests. It gets converted into several metabolites in animals and humans but mainly to fipronil sulfone, which is more toxic and persistent. Therefore, the current study aimed to investigate the presence of fipronil and fipronil sulfone in tissues of internal organs of white albino rats using gas chromatography coupled with mass spectroscopy (GC-MS) after oral administration of rats of repetitive sublethal doses of fipronil for 14 days. Results showed that the $\mathrm{R}^{2}$ values of standard curves of detected compounds were 0.9871 and 0.9989 for FIP and fipronil sulfone, respectively with LOQ of fipronil and fipronil sulfone of 5 and $10 \mu \mathrm{g} / \mathrm{g}$. Average recovery percentages were from $96.3 \pm 5.4$ to $101 \pm 8.5 \%$ and $93.8 \pm 4.7$ to $98.4 \pm 5.1 \%$ for fipronil and fipronil sulfone, respectively with RSD values lower than $10 \%$. Fipronil was detected in all tested organs. It was concentrated with great amounts in the lungs, liver, and kidney followed by testes, spleen, and brain, while fipronil sulfone was detected in the liver, testes, spleen, and lungs tissues in descending order. Fipronil was biotransformed into fipronil sulfone at different organs of white albino rats and the GC-MS coupled with the QuEChERS extraction and clean-up method were efficient in detecting them in the internal organs of rats.
\end{abstract}

Keywords: Fipronil; Fipronil Sulfone; Metabolism; Internal Animal Organs; GC-MS.

\section{Introduction}

Fipronil (FIP) is a contact and stomach new insecticide with a good selectivity between insects and mammals via blocking the $\gamma$-aminobutyric acid-gated chloride (GABA) channels. Fipronil contains a trifluoromethyl sulfinyl moiety that is unique among the agrochemicals and therefore, presumably important in its outstanding performance (Hainzl \& Casida 1996; Hainzl et al. 1998). It is widely used to control common household and plant pests such as termites, ants, spiders, and mosquitoes. It is a widespread urban-use insecticide that has acute toxicity to arthropods at low levels (Hainzl et al. 1998; Ikeda et al. 2004; Gan et al. 2012). FIP (phenylpyrazole) is known to cause mild neurological and dermatological effects. However, fipronil was reported to cause a variety of toxic effects on animals and humans, such as neurotoxic, hepatotoxic, nephrotoxic, reproductive, and cytotoxic effects on vertebrate and invertebrates (Wang et al. 2016).

Fipronil is metabolized into fipronil sulfone, sulfide, desulfinyl, and amide in mammals such as rats, humans, livestock species, and dogs (Roques et al. 2012). Biotransformation of FIP into fipronil sulfone is done by the hepatic cytochromes P450 (Roques et al. 2012). Fipronil and its sulfone metabolite raised the concerns about their environmental and human health effects, where they were reported as a thyroid disruptor (Tingle et al. 2003; Roques et al. 2012). The sulfone is more persistent in the organisms than fipronil (Roques et al. 2012). The concentrations of fipronil sulfone in rat plasma was at least 20-fold higher than fipronil (Lacroix et al. 2010). Therefore, it might exert more toxic effects on mammals as neurotoxic to rats and mild nervous toxicities in humans compared to FIP (Gunasekara et al. 2007).

Monitoring FIP and its residues in animals, human, and environmental samples is critical and was attempted by several authors. Quantification of fipronil and its metabolites (sulfone, sulfide, desulfinyl, and amide) in human and animal specimens including urine and plasma was done by gas or liquid chromatography (GC or LC) coupled to mass spectrometry (MS) (Vílchez et al. 2001; Kadar \& Faucon 2006; Bichon et al. 2008) or electron capture detection (GC-ECD) in animal tissues (Hainzl et al. 1998; Jiménez et al. 2008). The GC-MS/MS (validated according to the European standard 2002/657/EC) was employed in screening fipronil residues in ovine plasma (Bichon et al. 2008). Also, HPLC method with UV detection (Leghait et al. 2009) was used for fipronil determination in rats' plasma and showed that fipronil was actively metabolized to its sulfone derivative. The reversed-phase LC-UV (at $210 \mathrm{~nm}$ ) was efficient in the determination of fipronil in bovine plasma after SPE extraction (SPE) (Cid et al. 2012), plasma samples using GC-MS/MS (Bichon et al. 2008), LC-UV/MS and GC-MS, LC-MS/MS in animal urine samples (Cravedi et al. 2013), in human and rodents urine and serum sample using the liquid chromatography/time-of-flight mass spectrometer (LC/TOF-MS) (McMahen et al. 2015), and in blood samples of rat and human using LC-MS/MS (Raju et al. 2016). Fipronil and its residues were extracted using solid-phase microextraction (SPME; fused-silica fiber coated with $85 \mathrm{~mm}$ polyacrylate) (Vílchez et al. 2001), Quick, Easy, Cheap, Effective, Rugged, and Safe (QuEChERS) (Tomasini et al. 2011), and matrix solid-phase dispersion (MSPD) (Kadar \& Faucon 2006; Le Faouder et al. 2007; Bichon et al. 2008). 
Because of the limited studies that investigate the movement and transformation of fipronil in various internal tissues of mammals, the current study aimed to detect and determine fipronil and fipronil sulfone in tissues of internal organs of white albino rats using gas chromatography coupled with mass spectroscopy (GC-MS) after oral administration of rats of repetitive sublethal doses of fipronil for 14 days.

\section{Materials and methods}

\subsection{Chemicals}

Fipronil solution $\left(4.85 \mathrm{mg} / \mathrm{kg}\right.$ bwt $\left.\left(1 / 20 \mathrm{LD}_{50}\right)\right)$ was prepared from a commercial product called Fiprogent ${ }^{\circledR}$ WB $80 \%$ in demineralized water. Acetonitrile, triphenyl phosphate (TPP), acetone, glacial acetic acid, and QuEChERS extraction and clean-up kits (Agilent Technologies catalog \# 5982-0650 and 5982-5056, respectively) were purchased from the Arabian Group for Integrated Technologies (AGITECH), Cairo, Egypt. Standard materials of fipronil and fipronil sulfone (Sigma Cat.\# 46451-100MG and 32333-50MG, respectively) were used to construct the standard curves (Fig. 1).

\subsection{Experimental procedures and tissue collection}

Fourteen healthy adult male albino rats (average weight of each rat was $100 \pm 10 \mathrm{~g}$ ) were obtained from the Animal Breeding Unit, Faculty of Agriculture, Alexandria University. They were housed in cages with controlled temperature $\left(25 \pm 2{ }^{\circ} \mathrm{C}\right)$, relative humidity $50-70 \%$, twelve hours dark/light cycle and ad libitum access to food and water. The animal experiments were performed in accordance with the Guidelines for the Care and Use of Laboratory Animals of the National Institutes of Health (NIH) (Thompson et al. 2002). After 14 days of acclimatization, the rats were randomly divided equally into two experimental groups of seven rats per group. Group1: control group rats were orally received saline and group 2: animals have orally received FIP solution $(4.85 \mathrm{mg} / \mathrm{kg}$ bwt, $1 / 20$ of the LD 50 (Tomlin 2000)) for 14 days daily. On the $15^{\text {th }}$ day, rats were anesthetized with diethyl ether and sacrificed by cervical decapitation. The brain, liver, lungs, kidney, spleen, and testes tissues were excised and rapidly stored at $-80^{\circ} \mathrm{C}$ until being used for the extraction of fipronil and fipronil sulfone.

\subsection{Extraction and clean-up of fipronil and fipronil sulfone}

Modified QuEChERS extraction method (Usui et al. 2012; Nassar et al. 2016) was used for the determination of fipronil and fipronil sulfone. About $1 \mathrm{~g}$ of internal tissue organs was homogenized in $10 \mathrm{~mL}$ of $0.1 \%$ acidified acetonitrile. Tubes were vortexed for $1 \mathrm{~min}$ at maximum speed and $4 \mathrm{~g}$ of $\mathrm{MgSO}_{4}$ (anhy.) and $1 \mathrm{~g} \mathrm{NaCl}$ were added to each tube and vortexed for $1 \mathrm{~min}$. A $50 \mu \mathrm{L}$ of TPP (internal standard) solution was mixed in each tube for $30 \mathrm{~s}$. Extracts were centrifuged for $10 \mathrm{~min}$ at $4000 \mathrm{rpm}$ at $4{ }^{\circ} \mathrm{C}(\mathrm{Hermle} \mathrm{Labortechnik} \mathrm{GmbH}$, Siemensstr25 D-78564 Wehingen, Germany). Approximately, $1 \mathrm{~mL}$ of acetonitrile layer was transferred to $5 \mathrm{~mL}$ tubes containing $25 \mathrm{mg}$ PSA sorbent and $150 \mathrm{mg}$ anhydrous $\mathrm{MgSO}_{4}$. Tubes were capped tightly and shaken by hand for $5 \mathrm{~min}$. Samples were centrifuged for 5 min at $4000 \mathrm{rpm}$. Samples were extracted and cleaned up in triplicates. About $0.5 \mathrm{~mL}$ of extracts was transferred into amber HPLC vials for GC/MS analysis.

\subsection{GC-MS analysis}

Samples were analyzed with a gas chromatography system model 7890B coupled with mass spectrometry model 5977A (GC-MS) instrument and an autosampler (Agilent, Little Falls, DE). The system was equipped with a split/splitless injection inlet, and electronic pressure control (EPC). The system was controlled by MSD ChemStation software (version F.01.03.2357) and data analysis was done by MassHunter GC/MS acquisition software (version B.07.03.2139). Extracts and recovery samples $(2 \mu \mathrm{L})$ were injected in the GC-MS system in splitless mode. An HP-5 capillary column ( $30 \mathrm{~m} \mathrm{X} 0.53 \mathrm{~mm}$ i.d. $0.25 \mu \mathrm{m}$ film thickness) was used to separate the components. Helium was used as a carrier gas. Separation conditions were according to the AOAC (2007) as the following: initial column temperature set at $80^{\circ} \mathrm{C}$ for $6 \mathrm{~min}$., increased to $215^{\circ} \mathrm{C}$ at $15^{\circ} \mathrm{C} / \mathrm{min}$ (hold for $1 \mathrm{~min}$ ), then to $230^{\circ} \mathrm{C}$ at $5^{\circ} \mathrm{C} / \mathrm{min}$ and finally to $290^{\circ} \mathrm{C}$ at $5^{\circ} \mathrm{C} / \mathrm{min}($ hold for 2 $\mathrm{min}$ ). The carrier gas was at a constant flow rate of $1.1 \mathrm{~mL} / \mathrm{min}$. Fipronil and fipronil sulfone were identified by their full mass spectra scans and retention time using the total ion current as a monitor to give a Total Ion Chromatogram (TIC). The use of the full scan mode allowed the contrast of the spectrum of the compounds with the EI-MS library.

\subsection{Quality control}

Method quality control included the estimation of the limit of quantification, linearity, accuracy, and precision of the method and equipment (Branch 2005; Lacroix et al. 2010; FDA 2018).

\subsection{Statistical analysis}

Results of the detected areas under the curve of each compound were used to calculate the unknown concentration of fipronil and fipronil sulfone based on standard curves. Mean concentrations of each compound that were detected in different tissue were statistically analyzed using the General Linear Model (GLM) procedure of the Statistical Analysis System (SAS) software version 9.3 (SAS 2016) as a Completely Randomized Design (CRD).

\section{Results and discussion}

\subsection{Linearity}

Calibration curves were fitted using levels ranging from 0.1 to $50 \mu \mathrm{g} / \mathrm{g}$ of the two compounds. Each calibration-level was injected in triplicate and peak areas of analytes were plotted versus analytes concentrations. Regression equation from each calibration curve of the respected compound was used to calculate unknown concentrations. Also, the $\mathrm{R}^{2}$ values were found to be 0.9871 and 0.9989 for FIP and 
fipronil sulfone, respectively as shown in Fig. 1, which highlighted the suitability of the employed method for the estimation of tested compounds.
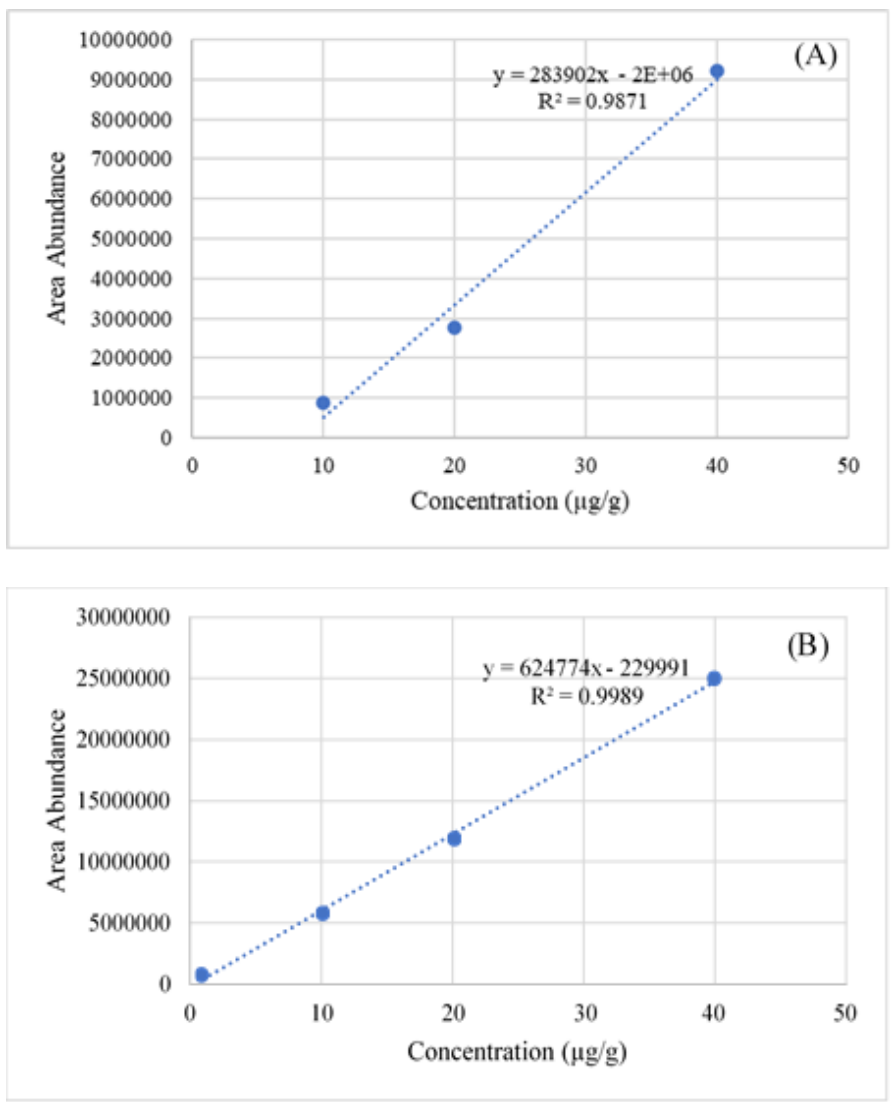

Fig. 1: Standard Curves of Fipronil (A) and Fipronil Sulfone (B) After Running Different Levels of Each Compound on the GC-MS.

\subsection{Method limit of quantification (LOQ), precision, and accuracy}

The method detection limit (LOD) and quantification limit (LOQ) were determined as 3 and 10 times the standard deviation, respectively of the signal of the blank sample. The LOQ of fipronil and fipronil sulfone were 5 and $10 \mu \mathrm{g} / \mathrm{g}$, respectively (Table 1). Previous results reported that after a repeated oral administration, fipronil concentrations in rat plasma were lower than the LOQ $(<100 \mathrm{ng} / \mathrm{mL})$ while fipronil sulfone concentrations ranged from 1 to $2 \mu \mathrm{g} / \mathrm{mL}$ (Lacroix et al. 2010). The LOQ of fipronil sulfone was $5 \mathrm{ng} / \mathrm{mL}$ (Cid et al. 2012) and it ranged from $0.05-0.16$ and $0.28-0.73 \mu \mathrm{g} / \mathrm{mL}$ for fipronil and fipronil sulfone, respectively (Bichon et al. 2008).

Blank (control group of rats) samples were spiked with 3 levels $(1,5,10 \mu \mathrm{g} / \mathrm{g}$ ) of each compound and were read in triplicates. Fipronil or fipronil sulfone were not detected in the blank samples. Results of spiked samples showed that the average recovery percentages were from $96.3 \pm 5.4$ to $101 \pm 8.5 \%$ and $93.8 \pm 4.7$ to $98.4 \pm 5.1 \%$ for fipronil and fipronil sulfone, respectively with RSD \% lower than $10 \%$ (Table 1 ). Similar results were reported for fipronil, desulfinyl fipronil, and other compounds where the recovery values exceeded $95 \%$ for all three compounds (Hainzl \& Casida 1996). Moreover, no other peaks were detectable at the retention times of fipronil or fipronil sulfone (Fig. 2).

Table 1: Coefficients of Variation (CV\%) expressed as Intra- and Inter-Assay, Recovery Percentages \pm Relative Standard Deviation (RSD\%) Values of Fipronil and Fipronil Sulfone in Spiked Samples of Internal Organs of the Control Group of Rats, and Limits of Quantification (LOQ)

\begin{tabular}{|c|c|c|c|c|c|c|c|}
\hline \multirow{2}{*}{ Compound } & \multirow{2}{*}{ Organ } & \multicolumn{2}{|c|}{$\mathrm{CV} \%$} & \multicolumn{3}{|c|}{ Recovery $(\mu \mathrm{g} / \mathrm{g}) \pm \mathrm{RSD} \%$} & \multirow{2}{*}{ LOQ $(\mu \mathrm{g} / \mathrm{g})$} \\
\hline & & Inter-Assay & Intra-Assay & 1 & 5 & 10 & \\
\hline \multirow{6}{*}{ Fipronil } & Brain & 4.3 & 8.2 & $96.7 \pm 7.1$ & $97.2 \pm 6.8$ & $100 \pm 8.2$ & \multirow{6}{*}{5} \\
\hline & Kidney & 4.8 & 8.4 & $97.3 \pm 6.8$ & $98.9 \pm 8.1$ & $99.9 \pm 5.6$ & \\
\hline & Liver & 3.6 & 8.3 & $96.3 \pm 5.4$ & $99.2 \pm 6.9$ & $99.2 \pm 6.1$ & \\
\hline & Lungs & 5.1 & 8.1 & $99.4 \pm 8.3$ & $99.9 \pm 8.7$ & $99.6 \pm 6.8$ & \\
\hline & Spleen & 5.2 & 7.9 & $98.6 \pm 6.7$ & $99.8 \pm 8.1$ & $96.8 \pm 7.2$ & \\
\hline & Testes & 5.9 & 8.8 & $99.7 \pm 5.9$ & $101 \pm 8.5$ & $97.5 \pm 8.2$ & \\
\hline \multirow{6}{*}{ Fipronil Sulfone } & Brain & 4.9 & 8.3 & $94.8 \pm 3.9$ & $94.5 \pm 4.3$ & $96.8 \pm 6.8$ & \multirow{6}{*}{10} \\
\hline & Kidney & 5.1 & 8.5 & $93.9 \pm 3.8$ & $93.8 \pm 4.7$ & $93.9 \pm 5.1$ & \\
\hline & Liver & 3.7 & 8.7 & $95.7 \pm 4.5$ & $95.6 \pm 5.8$ & $98.2 \pm 7.5$ & \\
\hline & Lungs & 5.2 & 8.1 & $94.8 \pm 5.1$ & $96.8 \pm 4.9$ & $96.5 \pm 5.9$ & \\
\hline & Spleen & 6.4 & 7.9 & $96.8 \pm 6.1$ & $98.4 \pm 5.1$ & $99.1 \pm 6.6$ & \\
\hline & Testes & 7.1 & 7.4 & $98.3 \pm 5.3$ & $98.2 \pm 5.4$ & $97.5 \pm 5.6$ & \\
\hline
\end{tabular}

Intra-day and inter-day precisions (Abbassy et al. 2015) and accuracy of fipronil and fipronil sulfone were calculated from reading quality control samples at different concentration levels on the same day and on different days, respectively. The results were given in Table 1 . The precision of the methods was expressed as the relative standard deviation (\% RSD). Accuracy was calculated as mean recovery percent (\%) (Lacroix et al. 2010; FDA 2018). Results in Table 1 showed that the GC-MS after QuEChERS extraction is reliable and precise to be used in the determination of the two compounds in rats' tissues. 


\subsection{Fipronil and fipronil sulfone in rats' internal organs}

Current results showed that the GC-MS coupled with the QuEChERS extraction and clean-up detected fipronil and fipronil sulfone in internal organs of rats (Fig. 2 and Fig. 3).

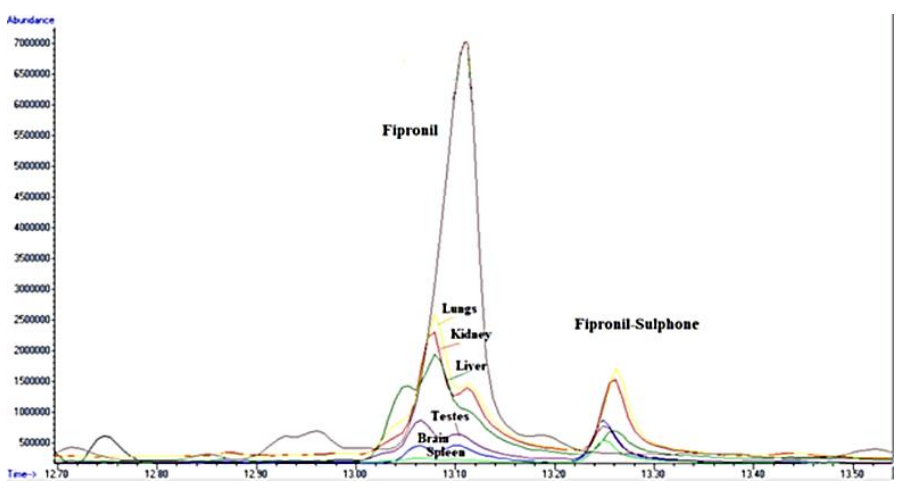

Fig. 2: Chromatogram of Separation of Fipronil and Fipronil Sulfone Detected in Different Internal Organs of Treated Rats.
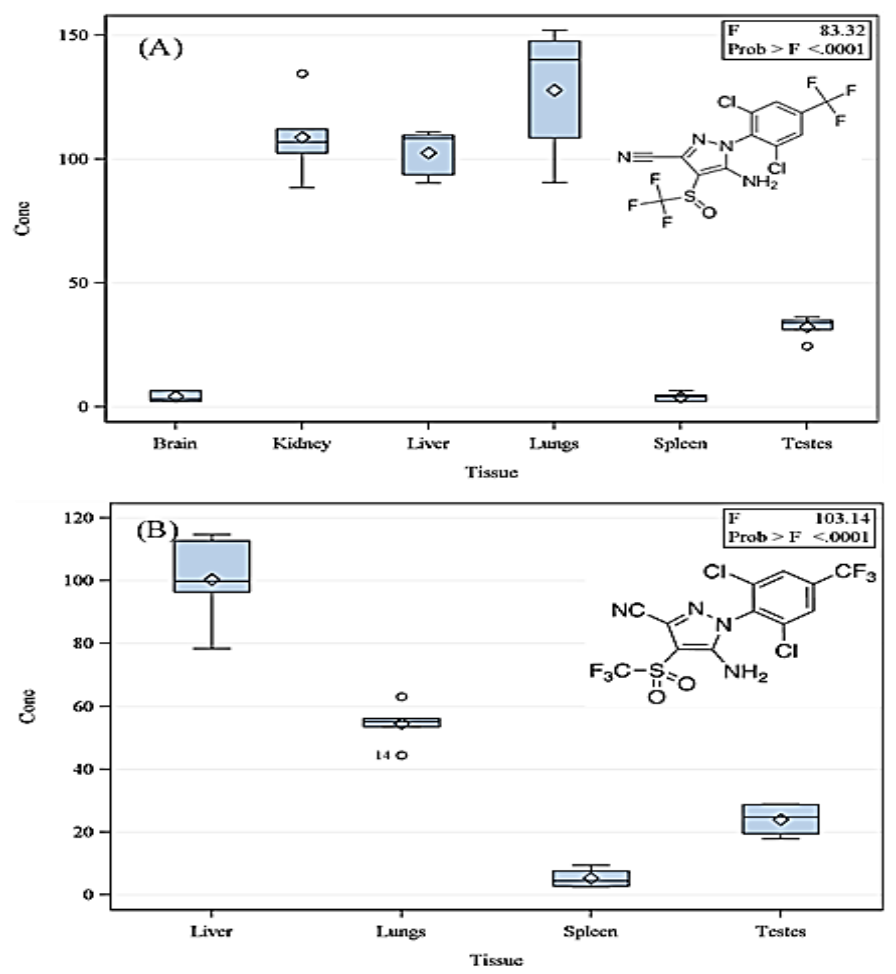

Fig. 3: Mean Values of Detected Fipronil (A) and Fipronil Sulfone (B) in Various Tissues of Internal Organs of White Albino Rats That were Given Oral Doses Equal to $1 / 20$ of $\mathrm{LD}_{50}$ of Fipronil Insecticide for 14 Consecutive Days.

Results in Fig. 3A showed that after administering rats with repeated oral doses of fipronil, it was detected in all tested organs. Its concentration was different from organ to the other, where great amounts detected in the lungs, liver, and kidney followed by testes, spleen, and brain in a descending order. On the other hand, fipronil sulfone (Fig. 3B) was detected in the liver, testes, spleen, and lungs tissues in a descending order. The concentration of fipronil and fipronil sulfone ranged from 6 to 140 and 4 to $114 \mu \mathrm{g} / \mathrm{g}$, respectively. The wide range might be due to the repeated exposure to fipronil.

The biotransformation of fipronil to fipronil sulfone was done by hepatic cytochromes $\mathrm{P}_{450}$ (Roques et al. 2012). The fipronil sulfone is more toxic and persistent than the fipronil itself, where it acts also as a thyroid disruptor (Roques et al. 2012). Also, in rats and humans, fipronil converts into fipronil sulfone, which is more persistent with half-life of $208 \mathrm{~h}$ compared to fipronil $8.5 \mathrm{~h}$ (Raju et al. 2016). Similar to results reported in the current study, it was reported that the major metabolite of fipronil is the sulfone and was detected in the brain, liver, kidney, fat, and feces of mice using GC and HPLC methods (Hainzl \& Casida 1996; Gunasekara et al. 2007). Also, Roques et al. (2012) mentioned that fipronil was metabolized into fipronil sulfone in rats, humans, livestock species, and dogs. Lacroix et al. (2010) reported that fipronil was metabolized to fipronil sulfone and its concentrations in plasma were at least 20-fold higher than those of fipronil. The analyses were conducted using LC/UV/MS/MS method. Fipronil and its metabolites were detected in adipose tissue (83\%), adrenals (90\%), liver (92\%), kidney (98\%), testis (88\%), and brain (90\%) (Cravedi et al. 2013).

\section{Conclusion}

Fipronil is a widespread insecticide against a wide range of pests. It is biotransformed mainly into fipronil sulfone, which is more toxic to animal and human. Estimation of fipronil and fipronil sulfone in tissues of internal organs of white albino rats was done using gas chromatography coupled with mass spectroscopy (GC-MS) after extraction and clean-up with the QuEChERS method. Fipronil and fipronil 
sulfone were detected in internal organs with concentrations ranged from 6 to 140 and 4 to $114 \mu \mathrm{g} / \mathrm{g}$, respectively. More studies are urged to investigate the adverse effects of fipronil and fipronil sulfone on different biological activity and organs.

\section{Acknowledgments}

The author would like to thank Dr. Atef MK Nassar, Plant Protection Department, Faculty of Agriculture, Damanhour University for revising the manuscript. Also, the author would like to acknowledge the staff members of Pesticides Residues Analysis and Toxicity Laboratory, Faculty of Agriculture, Damanhour University for running the GC-MS analyses.

\section{Disclosure statement}

No competing financial interests exist.

\section{References}

[1] Abbassy MA, Nassar AMK, Salim YMM, \& Marzouk MA (2015) Toxic effects of residue amounts of chlorpyrifos-methyl in tomato to white albino rats. Res J Environ Toxicol 9:241-250. https://doi.org/10.3923/rjet.2015.241.250.

[2] AOAC (2007) Pesticide Residues in Foods by Acetonitrile Extraction and Partitioning with Magnesium Sulfate Gas Chromatography/Mass Spectrometry and Liquid Chromatography/Tandem Mass Spectrometry First Action 2007. AOAC Int, Gaithersburg, USA

[3] Bichon E, Richard CA, \& Le Bizec B (2008) Development and validation of a method for fipronil residue determination in ovine plasma using 96well plate solid-phase extraction and gas chromatography-tandem mass spectrometry. J Chromatogr A 1201:91-99. https://doi.org/10.1016/j.chroma.2008.06.024.

[4] Branch SK (2005) Guidelines from the International Conference on Harmonisation (ICH). J. Pharm. Biomed. Anal. 38:798-805 https://doi.org/10.1016/j.jpba.2005.02.037.

[5] Cid YP, Ferreira TP, Medeiros DMVC, et al (2012) Determination of fipronil in bovine plasma by solid-phase extraction and liquid chromatography with ultraviolet detection. Quim Nova 35:2063-2066. https://doi.org/10.1590/S0100-40422012001000029.

[6] Cravedi JP, Delous G, Zalko D, et al (2013) Disposition of fipronil in rats. Chemosphere 93:2276-2283. https://doi.org/10.1016/j.chemosphere.2013.07.083.

[7] FDA (2018) Bioanalytical Method Validation Guidance for Industry

[8] Gan J, Bondarenko S, Oki L, et al (2012) Occurrence of fipronil and its biologically active derivatives in urban residential runoff. Environ Sci Technol 46:1489-1495. https://doi.org/10.1021/es202904x.

[9] Gunasekara AS, Truong T, Goh KS, et al (2007) Environmental fate and toxicology of fipronil. J Pestic Sci 32:189-199. https://doi.org/10.1584/jpestics.R07-02.

[10] Hainzl D \& Casida JE (1996) Fipronil insecticide: Novel photochemical desulfinylation with retention of neurotoxicity. Proc Natl Acad Sci 93:12764-12767. https://doi.org/10.1073/pnas.93.23.12764.

[11] Hainzl D, Cole LM, \& Casida JE (1998) Mechanisms for selective toxicity of fipronil insecticide and its sulfone metabolite and desulfinyl photoproduct. Chem Res Toxicol 11:1529-1535. https://doi.org/10.1021/tx980157t.

[12] Ikeda T, Nagata K, Kono Y, et al (2004) Fipronil modulation of GABAA receptor single-channel currents. Pest Manag Sci 60:487-492. https://doi.org/10.1002/ps.830.

[13] Jiménez JJ, Bernal JL, del Nozal MJ, et al (2008) Sample preparation methods to analyze fipronil in honey by gas chromatography with electroncapture and mass spectrometric detection. J Chromatogr A 1187:40-45. https://doi.org/10.1016/j.chroma.2008.02.014.

[14] Kadar A \& Faucon J-P (2006) Determination of Traces of Fipronil and Its Metabolites in Pollen by Liquid Chromatography with Electrospray Ionization-Tandem Mass Spectrometry. J Agric Food Chem 54:9741-9746. https://doi.org/10.1021/jf062035.

[15] Lacroix MZ, Puel S, Toutain PL, \& Viguié C (2010) Quantification of fipronil and its metabolite fipronil sulfone in rat plasma over a wide range of concentrations by LC/UV/MS. J Chromatogr B Anal Technol Biomed Life Sci 878:1934-1938. https://doi.org/10.1016/j.jchromb.2010.05.018.

[16] Le Faouder J, Bichon E, Brunschwig P, et al (2007) Transfer assessment of fipronil residues from feed to cow milk. Talanta 73:710-717. https://doi.org/10.1016/j.talanta.2007.04.061.

[17] Leghait J, Gayrard V, Picard-Hagen N, et al (2009) Fipronil-induced disruption of thyroid function in rats is mediated by increased total and free thyroxine clearances concomitantly to increased activity of hepatic enzymes. Toxicology 255:38-44. https://doi.org/10.1016/j.tox.2008.09.026.

[18] McMahen RL, Strynar MJ, Dagnino S, et al (2015) Identification of fipronil metabolites by time-of-flight mass spectrometry for application in a human exposure study. Environ Int 78:16-23. https://doi.org/10.1016/j.envint.2015.01.016.

[19] Nassar AMK, Salim YM, \& Malhat FM (2016) Assessment of Pesticide Residues in Human Blood and Effects of Occupational Exposure on Hematological and Hormonal Qualities. Pakistan J Biol Sci. https://doi.org/10.3923/pjbs.2016.95.105.

[20] Raju KSR, Taneja I, Rashid M, et al (2016) DBS-platform for biomonitoring and toxicokinetics of toxicants: Proof of concept using LC-MS/MS analysis of fipronil and its metabolites in blood. Sci Rep 6:1-9. https://doi.org/10.1038/srep22447.

[21] Roques BB, Lacroix MZ, Puel S, et al (2012) CYP450-Dependent biotransformation of the insecticide fipronil into fipronil sulfone can mediate fipronil-induced thyroid disruption in rats. Toxicol Sci 127:29-41. https://doi.org/10.1093/toxsci/kfs094.

[22] SAS (2016) Statistical Analysis System. Version 9.3.

[23] Thompson M, Ellison SLR, \& Wood R (2002) Harmonized guidelines for single-laboratory validation of methods of analysis (IUPAC Technical Report). Pure Appl Chem 74:835-855. https://doi.org/10.1351/pac200274050835.

[24] Tingle CCD, Rother JA, Dewhurst CF, et al (2003) Fipronil: environmental fate, ecotoxicology, and human health concerns. Rev. Environ. Contam. Toxicol. 176:1-66 https://doi.org/10.1007/978-1-4899-7283-5_1.

[25] Tomasini D, Sampaio MRF, Cardoso L V., et al (2011) Comparison of dispersive liquid-liquid microextraction and the modified QuEChERS method for the determination of fipronil in honey by high performance liquid chromatography with diode-array detection. Anal Methods 3:1893-1900. https://doi.org/10.1039/c1ay05221g.

[26] Tomlin C (2000) The pesticide manual: a world compendium. British Crop Protection Council

[27] Usui K, Hayashizaki Y, Hashiyada M, \& Funayama M (2012) Rapid drug extraction from human whole blood using a modified QuEChERS extraction method. Leg Med 14:286-296. https://doi.org/10.1016/j.legalmed.2012.04.008.

[28] Vílchez JL, Prieto A, Araujo L, \& Navalón A (2001) Determination of fipronil by solid-phase microextraction and gas chromatography-mass spectrometry. J Chromatogr A 919:215-221. https://doi.org/10.1016/S0021-9673(01)00788-9.

[29] Wang X, Martínez MA, Wu Q, et al (2016) Fipronil insecticide toxicology: oxidative stress and metabolism. Crit Rev Toxicol 46:876-899. https://doi.org/10.1080/10408444.2016.1223014. 